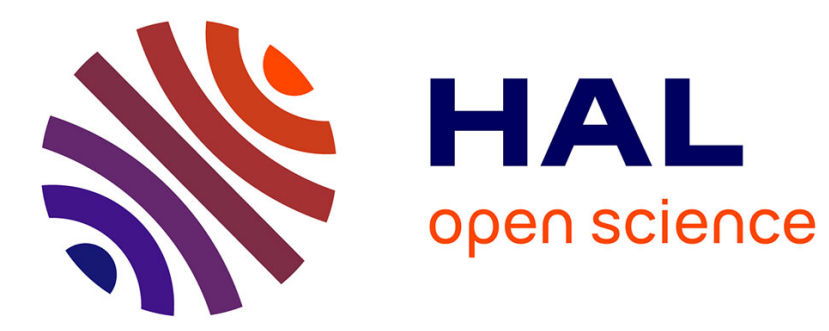

\title{
Synthesis and Properties of Higher Nuclearity Polyazanes
}

Thomas Criton, Debora Vilona, Guy Jacob, Maurice Médebielle, Elise Dumont, Lionel Joucla, Emmanuel Lacote

\section{To cite this version:}

Thomas Criton, Debora Vilona, Guy Jacob, Maurice Médebielle, Elise Dumont, et al.. Synthesis and Properties of Higher Nuclearity Polyazanes. Chemistry - A European Journal, 2020. hal-03089670

\section{HAL Id: hal-03089670 \\ https://univ-lyon1.hal.science/hal-03089670}

Submitted on 28 Dec 2020

HAL is a multi-disciplinary open access archive for the deposit and dissemination of scientific research documents, whether they are published or not. The documents may come from teaching and research institutions in France or abroad, or from public or private research centers.
L'archive ouverte pluridisciplinaire HAL, est destinée au dépôt et à la diffusion de documents scientifiques de niveau recherche, publiés ou non, émanant des établissements d'enseignement et de recherche français ou étrangers, des laboratoires publics ou privés. 


\title{
Synthesis and Properties of Higher Nuclearity Polyazanes
}

\author{
Thomas Criton, ${ }^{[\mathrm{a}]}$ Debora Vilona, ${ }^{[\mathrm{a}]}$ Guy Jacob, ${ }^{[\mathrm{a}]}$ Maurice Médebielle, ${ }^{[\mathrm{b}], *}$ Elise Dumont, ${ }^{[\mathrm{c}], \star}$ Lionel \\ Joucla, ${ }^{[\mathrm{a}], *}$ Emmanuel Lacôte ${ }^{[\mathrm{a}], *}$
}

\begin{abstract}
Polyazanes (that is, higher nuclearity homologues of hydrazines) with increasing numbers of bound nitrogen atoms (from 3 to 5) were prepared via additions of lower order polyazanes to diazo reagents, including the first pentazane ever described. A structure was obtained. It was shown that the polynitrogen chains adopt a helical conformation. DFT modeling shows that the arrangement subsists in solution. While the polyazanes are all reducing agents, they become less so with the increasing number of nitrogens.
\end{abstract}

Many heavier p-block elements lead to electronically precise homoatomic all $\sigma$ linear chains. ${ }^{[1]}$ For example, Silicon atoms can form homonuclear polysilanes, which are widely used for ceramics, as solar cells elements, etc. ${ }^{[2]}$ Sulfur forms over 30 allotropes, in particular rings, but other cyclic structures with catenated sulfur atoms (with or without additional Carbons in the rings) also exist, ${ }^{[3]}$ with important properties for biology or batteries. ${ }^{[4-6]}$ On the other hand, in the second period, and with the obvious exception of Carbon, $\sigma$-type single-element chains atoms are generally unstable. This is the case for oxygen, whose polyatomic chains can easily decompose to release dioxygen and oxidized compounds. That is a key for ozonolysis, where 3 contiguous oxygen atoms are initially part of a cycle..$^{[7-8]}$ Similarly, a linear 4-oxygens chain has been suggested as a key intermediate in radical hydroxylations. ${ }^{[9]}$

Hydrazines are well-known, reactivity-rich, 2-N molecules, where the two nitrogen atoms are single-bonded. ${ }^{[10]}$ The scenario quickly changes with higher nuclearities. Triazanes have been first synthesized decades ago, ${ }^{[11-13]}$ but little attention has been given to their properties. ${ }^{[14]}$ While tetrazenes, which feature both single and double-bonded nitrogen atoms, are stable moieties, only a handful of all $\sigma$ tetrazanes exist, ${ }^{[15-18]}$ and no higher order polyazane has ever been reported.

We approached this field when we noticed the dearth of data regarding the reactivity of even the smallest polyazanes, triazanes. We wanted to understand how chemical properties were affected by the addition of additional nitrogen atoms in the chain, and also to extend the chemical space of higher-order

[a] T. Criton, Dr. D. Vilona, Dr. G. Jacob, Dr. L. Joucla, Dr. E. Lacôte Univ Lyon, Univ Claude Bernard Lyon 1, CNRS, CNES ArianeGroup, LHCEP, UMR 5278

Bât. Raulin, 2 rue Victor Grignard, F-69622 Villeurbanne, France E-mail: lionel.joucla@univ-lyon1.fr, emmanuel.lacote@univ-lyon1.fr

[b] Dr. M. Médebielle

Univ Lyon, Univ Claude Bernard Lyon 1, CNRS, CPE Lyon, INSA Lyon, ICBMS, UMR 5246

Bât. Lederer, 1 rue Victor Grignard, F-69622 Villeurbanne, France E-mail: maurice.medebielle@univ-lyon1.fr

[c] Prof. E. Dumont

Univ Lyon, ENS Lyon, Univ Claude Bernard Lyon 1, CNRS, LCENS, UMR 5182

ENS de Lyon, 46 allée d'Italie, F-69364 Lyon cedex 07, France E-mail: elise.dumont@ens-lyon.fr

Supporting information for this article is given via a link at the end of the document.((Please delete this text if not appropriate)) polyazanes to longer chains. We report herein our initial results.

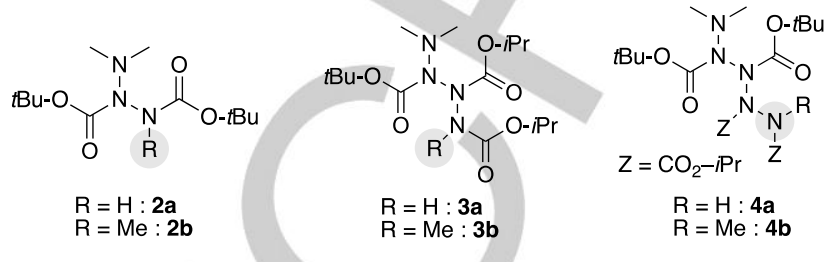

Figure 1. Target Polyazanes for this work

In order to get comparison points we targeted an assay of 6 polyazanes: two triazanes (2a-b), two tetrazanes (3a-b) and two pentazanes $(\mathbf{4 a - b})$. We assumed that because of all the consecutive lone pairs on the nitrogen atoms, the chains would be very electron-rich, and that the all $\sigma$ chains could be stabilized by the attachment of electron-withdrawing groups. Therefore, all the target polyazanes are built similarly. They feature a terminal amine (Figure 1, top nitrogens) substituted by two alkyl groups; all other nitrogens are substituted by carbamate groups; their $\omega$-end can be substituted either by a proton or a methyl.

Triazanes $\mathbf{2 a}$ and $\mathbf{2 b}$ were prepared using the Dreiding/Mayr methodology. ${ }^{[2,13]}$ Dimethylamine was added to di-tert-Butyl azodicarboxylate (DABD) in acetonitrile at rt, yielding $98 \%$ of $\mathbf{2 a}$. Triazane $\mathbf{2 b}$ was obtained in $86 \%$ yield upon methylation of the potassium salt of $2 \mathrm{a}$ in THF/DMF $(1: 1)$ at $0^{\circ} \mathrm{C}$.

While there are methods to access the unsaturated $4 \mathrm{~N}$ tetrazenes, e.g. by reaction of a nitrene derived from a hydrazine with a diazo reagent, ${ }^{[19-20]}$ or by oxidative coupling of hydrazines, ${ }^{[21-23]}$, there was only one method to access the saturated fully $\sigma$-bonded tetrazanes, i.e. the dimerization of captodative radicals (which can only deliver symmetric molecules). ${ }^{[15-18,24]}$ One report in the literature mentioned that an $\alpha$-sulfonyl anion serendipitously added sequentially to two equivalents of an azodicarboxylate. ${ }^{[25]}$ This suggested to us that hydrazinyl anions may be good reactive intermediates toward the formation of dissymmetric tetrazanes. We thus decided to prepare $3 \mathbf{a}$ and $\mathbf{3 b}$ by a nucleophilic addition $2 \mathrm{~N}+2 \mathrm{~N}$ route.

Boc-protected 1,1-dimethyl hydrazine 1a was deprotonated by Potassium bis(trimethylsilyl)amide (KHMDS) in a 1:1 THF/DMF mixture at $-80^{\circ} \mathrm{C}$, reacted with di-isopropyl azodicarboxylate (DIAD), and quenched with acetic acid at low temperature.
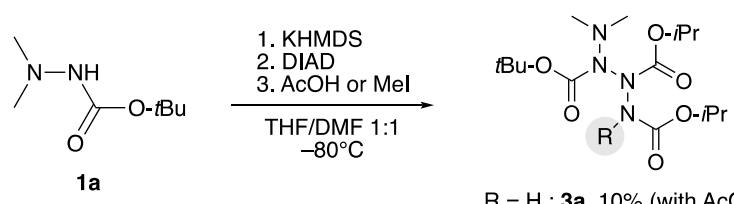

$\mathrm{R}=\mathrm{H}: \mathbf{3 a}, 10 \%$ (with $\mathrm{AcOH}$ ) $\mathrm{R}=\mathrm{Me}: \mathbf{3 b}, 70 \%$ (with Mel)

Scheme 1. Synthesis of the tetrazanes. 
Tetrazane 3a was obtained in a very poor $10 \%$ yield. It decomposed quickly at room temperature. We suspected that the decomposition was due to the presence of a proton on the chain. The methylation of the terminal $\mathrm{NH}$ position was achieved by trapping the intermediate anion at low temperature with Mel. Gratifyingly, 3b was thus obtained in $70 \%$ yield, and proved more stable.

For the unknown pentazanes, a similar retrosynthetic strategy required the addition of a triazane anion to an azodicarboxylate. Triazane 2a was first deprotonated with $\mathrm{NaH}$ in THF at $-40^{\circ} \mathrm{C}$, and the resulting anion was reacted with DIAD (Table 1, Entry 1) Unfortunately, no evolution was observed. When the solvent mix was made more polar by adding DMF, $65 \%$ of the desired pentazane $4 \mathbf{a}$ was isolated after quenching the reaction at low temperature with acetic acid (entries 2-3). Switching to KHMDS as the base further increased the yield by nearly $10 \%$ (entry 4 ). Furthermore, the reaction was complete after only 15 minutes (entry 5). A temperature increase to $-20^{\circ} \mathrm{C}$ led to a loss in yield (to $59 \%$, entry 6 ), while a lower temperature $\left(-80^{\circ} \mathrm{C}\right)$ resulted in a slower reaction (only $38 \%$ isolated yield after 15 minutes, entry 7). Therefore, the optimal conditions appear to be these of entry 5 , likely because of the better reactivity of the potassium anion of $2 \mathbf{a}$. When the quenching agent was exchanged to methyl iodide, pentazane $\mathbf{4 b}$ was isolated $(76 \%$, entry 8$)$.

Table 1. Optimization of the reaction conditions for the synthesis of Pentazanes $\mathbf{4 a}$ and $\mathbf{4 b}$ (Concentration was $0.2 \mathrm{M}$ )

\begin{tabular}{|c|c|c|c|c|c|}
\hline & 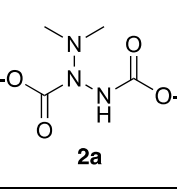 & $\begin{array}{l}\text { 1. } \mathrm{Bc} \\
\text { 2. } \mathrm{DI} \\
\text { 3. } \mathrm{Ac}\end{array}$ & or Mel & $\begin{array}{l}\mathrm{tBu}_{\mathrm{O}} \\
\mathrm{Z}=\mathrm{CO} \\
\end{array}$ & $\underbrace{O-t B u}_{O}$ \\
\hline Entry & Solvent & Base & $t(\min )$ & $\mathrm{T}\left({ }^{\circ} \mathrm{C}\right)$ & $\begin{array}{l}\text { Product } \\
\text { Yield (\%) }\end{array}$ \\
\hline $1^{[a]}$ & THF & $\mathrm{NaH}$ & 90 & -40 & $-[b]$ \\
\hline $2^{[a]}$ & THF/DMF (1:4) & $\mathrm{NaH}$ & 90 & -40 & $4 a, 65$ \\
\hline $3^{[\mathrm{a}]}$ & THF/DMF (1:1) & $\mathrm{NaH}$ & 90 & -40 & $4 a, 65$ \\
\hline $4^{[a]}$ & THF/DMF (1:1) & KHMDS & 90 & -40 & $4 a, 74$ \\
\hline $5^{[\mathrm{a}]}$ & THF/DMF (1:1) & KHMDS & 15 & -40 & $4 a, 74$ \\
\hline $6^{[\mathrm{a}]}$ & THF/DMF (1:1) & KHMDS & 15 & -20 & $4 a, 59$ \\
\hline $7^{[\mathrm{a}]}$ & THF/DMF (1:1) & KHMDS & 15 & -80 & $4 a, 38$ \\
\hline $8^{[c]}$ & THF/DMF (1:1) & KHMDS & 15 & -40 & $4 b, 76$ \\
\hline
\end{tabular}

[a] Reaction was quenched with $\mathrm{AcOH}$; [b] No reaction was observed; [c] Reaction was quenched with Mel.

The pentazanes proved stable over silica. They were identified by HRMS and the structure of $\mathbf{4 a}$ was confirmed by X-ray diffraction (see below). They are the first examples of molecules containing 5 contiguous nitrogen atoms bounds by single $\sigma$ bonds. In contrast, the ${ }^{1} \mathrm{H}$ NMR spectrum of 4 a was extremely complicated due to the presence of rotamers. We heated the samples at $80^{\circ} \mathrm{C}$ to get coalescence of the signals, but this resulted in a rapid decomposition. HRMS analysis of the decomposition products suggested that the pentazane had been cleaved in a mixture of hydrazines and triazanes. We presumed that the proton at the $\omega$ position enabled this decomposition. Indeed, the methylation of said position in $\mathbf{4 b}$ delivered a much more thermally stable pentazane. Its ${ }^{1} \mathrm{H}-\mathrm{NMR}$ analysis at $373 \mathrm{~K}$ led to a clean spectrum in which coalescence was achieved for almost all the signals.

With the array of polyazanes in hands, we could start the study of their properties, as well as how the latter change with the introduction of additional nitrogen atoms.

Crystal structure and conformation in solution. Crystals suitable for X-ray diffraction were obtained by slow evaporation of saturated solutions in diethyl ether at $0^{\circ} \mathrm{C}$. The X-ray structure of 2a shows the three $N$ atoms linked by $\sigma$ bonds. Starting from the $\mathrm{Me}_{2} \mathrm{~N}$ end, the bond lengths are $1.408 \AA$, and $1.383 \AA$. They are shorter than the bond length found in hydrazine $(1.446 \AA)$, but close to the one reported on carboxylate-protected 1,2-dimethyl hydrazine-1,2-dicarboxyl-ate $(1.386 \AA) .{ }^{[26]}$ The dimethylamino nitrogen displays a $\mathrm{sp}^{3}$ hybridization, and the remaining two nitrogen atoms are $\mathrm{sp}^{2}$ hybridized, albeit the sum of bond angles of the central atom is closer to $360^{\circ}$ than that of the terminal $\mathrm{sp}^{2}$ one $\left(357.8^{\circ}\right.$ vs. $\left.352.4^{\circ}\right)$. This difference reflects the influence of the carboxylate groups. The dihedral angle along the $\mathrm{N}$ chain is $105^{\circ}$ (Fig. 2). The two carboxylate groups generate a dihedral angle of $56.9^{\circ}$. The minimization of the steric hindrance between the $\mathrm{CO}_{2} \mathrm{R}$ groups explains the helical structure observed.

The X-ray structure of $\mathbf{4 a}$ follows the same trends. Starting from the $\mathrm{Me}_{2} \mathrm{~N}$ end, the bond lengths are $1.400 \AA$, $1.393 \AA$, $1.398 \AA$, and $1.386 \AA$. Apart from the dimethylamino nitrogen, which displays a $\mathrm{sp}^{3}$ hybridization (average bond angle of $111.9^{\circ}$ ), all the nitrogen atoms exhibit a $\mathrm{sp}^{2}$ hybridization. The dihedral angles along the $\mathrm{N}$ chain (starting from the $\mathrm{Me}_{2} \mathrm{~N}$ ) are $98.2^{\circ}$ and $86.2^{\circ}$ respectively for the all- $\mathrm{N}$ dihedra, resulting in a helical arrangement of the polyazane chain, which tends to minimize the repulsion between the $\mathrm{CO}_{2} \mathrm{R}$ groups (Fig. 2).
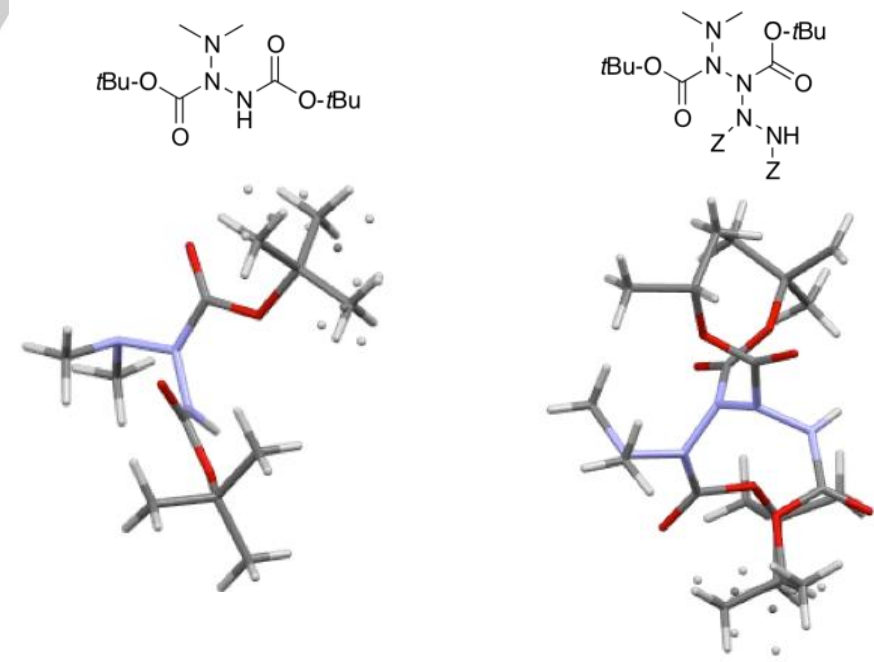

Figure 2. Structures of triazane $\mathbf{2 a}$ (left) and pentazane $\mathbf{4 a}$ (right). There is a slight disorder around the $t$-butyl groups, which can freely rotate; $\mathrm{Z}=\mathrm{CO}_{2} \mathrm{iPr}$. 
We optimized the polyazane structures through DFT calculations (see SI, Fig. S1). Interestingly, the computed solution structures overlap quite tightly with those in the crystal (except for the freely-rotating $t$-butyl groups). The calculated conformation for 3a, for which no structure could be obtained is similar to that of 4a with a helical arrangement. From this, we propose that the conclusions drawn for pentazanes are also valid for the tetrazanes. There is therefore a fair degree of periodicity in the polyazane family.

Redox properties. Hydrazines being well-known reducing agents, we examined how the redox properties are affected when additional nitrogens are linearly installed on a polyazane chain. We therefore measured the oxidation potentials of the polyazanes by cyclic voltammetry. The parent Boc-protected UDMH derivatives 1a (featuring an $\mathrm{N}-\mathrm{H}$ bond) and $\mathbf{1 b}$ (where the NBoc nitrogen is also methylated) were chosen as comparison points. The values obtained are reported in the third column of Table 2 .

Table 2. Electrochemical data for several polyazanes.

\begin{tabular}{llll}
\hline Entry & Compounds & $E_{o x}^{p}(\mathrm{~V})^{[\mathrm{a}]}$ & $E_{o x}^{p}(\mathrm{~V})^{[\mathrm{b}]}$ \\
\hline 1 & Hydrazine 1a & $\mathbf{0 . 8 2} ; 1.53 ; 1.75$ & $0.82(=)$ \\
2 & Hydrazine 1b & $\mathbf{0 . 9 6}$ & $0.92(-0.04)$ \\
3 & Triazane 2a & $\mathbf{1 . 2 2} ; 1.91$ & $1.31(+0.09)$ \\
4 & Triazane 2b & $\mathbf{1 . 1 9}$ & $1.23(+0.04)$ \\
5 & Tetrazane 3b & $\mathbf{1 . 3 2}$ & $1.43(+0.11)$ \\
6 & Pentazane 4a & $\mathbf{1 . 4 3}$ & $1.53(+0.10)$ \\
7 & Pentazane 4b & $\mathbf{1 . 4 9}$ & $1.51(+0.02)$ \\
\hline
\end{tabular}

[a] Anodic peak potential with a glassy carbon working electrode $(3 \mathrm{~mm})$ with

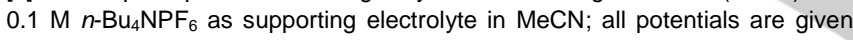
vs. SHE; [b] Computed absolute Redox Potential obtained through Born-Haber thermodynamic cycle at the M06-2X/6-31+G(d,p) level of theory, given vs. SHE (see ESI). Values in parenthesis correspond to the difference between the calculated and measured values of the first oxidation potential.

Boc-UDMH 1a exhibits an oxidation potential of $0.82 \mathrm{~V}$ ( vs. SHE, entry 1). Methylation of the nitrogen increases the potential to $0.96 \mathrm{~V}$ (entry 2). An additional nitrogen in the chain resulted in an increased anodic peak potential (1.22 V, entry 3$)$, which did not change by methylation of the terminal nitrogen $(1.19$ for $\mathbf{2 b}$, entry 4). The trend is maintained as additions of nitrogen atoms further increases the potential required for oxidation. Tetrazane $3 \mathbf{b}$, requires $1.32 \mathrm{~V}$ (entry 5), pentazane $4 \mathbf{a}$ requires $1.43 \mathrm{~V}$ (entry 6) and pentazane $\mathbf{4 b}$ requires $1.49 \mathrm{~V}$ (entry 7) to be oxidized, respectively. Tetrazane $3 a$ was not stable enough at room temperature to lead to significant results.

The oxidations are all irreversible, likely due to the short lifetime of the radical-cations generated. DFT calculations were therefore performed to locate the most oxidizable site in the polyazanes. The redox potential of all the molecules was estimated first through a Born-Haber thermodynamic cycle (see SI for details). ${ }^{[27]}$ Indeed, redox potentials are related to the
Gibbs free energy difference between the molecules in the oxidized state (radical cation species) and the solvated molecule in the ground state (neutral molecule). Geometry optimizations were then performed for both the neutral and radical cationic species at the DFT-M06-2X/6-31+G(d,p) level of theory, both in gas phase and solvated media with acetonitrile being treated implicitly.

The calculated ${ }^{[28]}$ redox potentials are in excellent agreement with the experimental ones (second column in Table 2, in brackets). The oxidation trend is well respected since Triazane $\mathbf{2 a}$ was found easier to oxidize than Tetrazane $\mathbf{3 b}$ and Pentazane 4a (Figure 3).

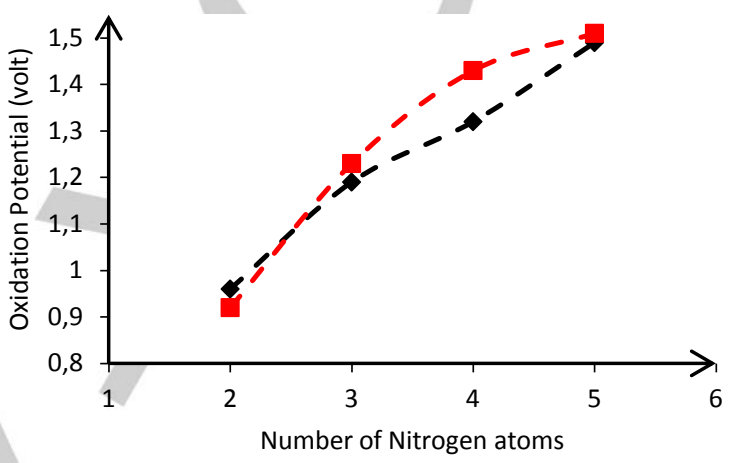

Figure 3. Evolution of the measured (black diamonds) and calculated (red squares) first redox potential of the polyazanes.

For the three systems, the spin density is mostly distributed between the nitrogens N1 and N2 (Figure 4). However, DFT inspection reveals interesting differences in the populations of the radical center. For triazane $\mathbf{2 a}$ and pentazane $\mathbf{4 a}$, the values identify $\mathrm{N} 1$ as the predominant radical center $(0.57$ and 0.65 respectively), whereas the unpaired electron is more delocalized for $\mathbf{3 b}$ with the first nitrogen bearing a spin density of $\sim 0.31$. For the three systems, the inter-nitrogen distances most affected by the oxidation are that of the N1-N2 bonds, which are shortened by $0.07 \AA$ upon one-electron oxidation. Conversely, the natural population analysis indicates that the nitrogen atoms sustain most of the cationic charge generated upon oxidation, with a total charge ranging between +0.5 and +0.7 a.u. (see ESI). For compounds $\mathbf{2 a}$ and $\mathbf{4 a}$, the first nitrogen is the most affected, with an increase of the atomic charged by +0.37 a.u., whereas the charge of the radical cation derived from $\mathbf{4 b}$ is distributed more equally over the two nitrogens, with a larger distribution of the remaining spin density contributions on the two others nitrogens and the carbonyl oxygens notably.

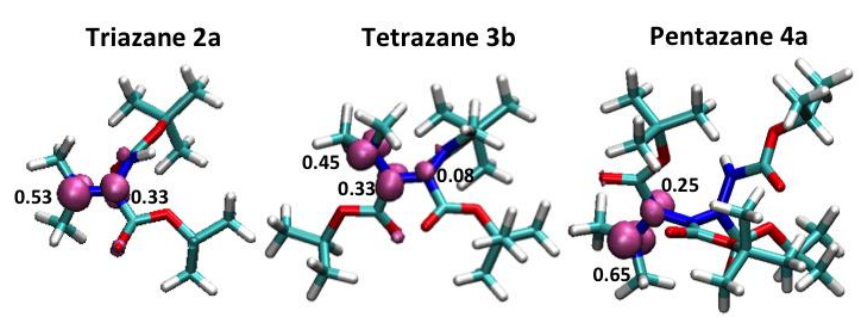


Figure 3. Cartoon representation of the structures of Triazane 2a, Tetrazane $3 a$ and Pentazane 4a in the radical cation form, optimized at the M06-2X/6$31+G(d, p)$ level of theory and spin density representation (isovalue 0.10 ).

Table 3. Computed nitrogen-nitrogen distances for Triazane 2a, Tetrazane $\mathbf{3 b}$ and Pentazane $\mathbf{4 a}$

\begin{tabular}{|c|c|c|c|c|c|c|c|c|c|}
\hline Polyazane & \multicolumn{2}{|c|}{$2 a$} & \multicolumn{3}{|c|}{$3 b$} & \multirow[b]{2}{*}{ N1-N2 } & \multirow[b]{2}{*}{ N2-N3 } & \multirow[b]{2}{*}{ N3-N4 } & \multirow[b]{2}{*}{ N4-N5 } \\
\hline Bond & N1-N2 & N2-N3 & N1-N2 & N2-N3 & N3-N4 & & & & \\
\hline $\begin{array}{l}\text { Radical } \\
\text { Cation }\end{array}$ & 1.33 & 1.37 & 1.33 & 1.36 & 1.37 & 1.34 & 1.37 & 1.37 & 1.37 \\
\hline $\begin{array}{l}\text { Neutral } \\
\text { molecule }\end{array}$ & 1.39 & 1.38 & 1.40 & 1.36 & 1.37 & 1.40 & 1.37 & 1.37 & 1.37 \\
\hline
\end{tabular}

The calculations indicate that the most oxidizable site is the nitrogen directly connected to the dimethyl substituents, since the electron is easily removed from it, but that there seems to be a difference between the odd-numbered polyazane (2a, $\mathbf{4 a}$ ) and the even-numbered one $(\mathbf{3 b})$. Perhaps this reflects the lower stability of the tetrazanes compared to both the tri- and pentazanes, as it develops a larger positive charge density next to a withdrawing group.

To conclude, polyazanes are a new class of nitrogen-containing molecules that until now had not been considered as a family with similar properties. We showed that this is indeed the case, as similarly substituted polyazanes with growing numbers of linked nitrogen atoms gradually fold to form helices and become increasingly less oxidizable. Further work will focus on enlarging the chemical space accessible (e. g. to longer, or branched chains) and unearthing new properties of these new main group oligomers.

\section{Acknowledgements}

We thank CNES, ArianeGroup, CNRS, CPE Lyon, Université Claude Bernard Lyon 1, ENS Lyon, the SYSPROD project, the AXELERA Pôle de Compétitivité (PSMN Data Center), Institut de Chimie de Lyon, and DGA \& Agence de l'innovation de défense for funding of this work. T. C. thanks DGA and CNRS for a Ph. D. stipend. D. V. thanks CNES for a postdoctoral grant.

\section{Keywords: Nitrogen • Oxidation • Molecular Modeling • Azo}

Compounds $\cdot$ Radical-Cations

[1] A. L. Rheingold, Homoatomic Rings, Chains and Macromolecules of Main-Group Elements, Elsevier: Amsterdam, 1977

[2] V. B. Kumar, E. M. Leitao, Appl. Organomet. Chem. 2020, 34, e5402.

[3] B. Meyer, Chem. Rev. 1964, 64, 429-451.

[4] G. Li, S. Wang, Y. Zhang, M. Li, Z. Chen, J. Lu, Adv. Mater. Weinh. Ger. 2018, 30, n/a.

[5] N. Lau, M. D. Pluth, Curr. Opin. Chem. Biol. 2019, 49, 1-8.

[6] R. Steudel, T. Chivers, Chem. Soc. Rev. 2019, 48, 3279-3319.

[7] R. Criegee, Angew. Chem. 1975, 87, 765.

[8] C. Geletneky, S. Berger, Eur. J. Org. Chem. 1998, 1625-1627.

[9] S. L. Khursan, "Organic tetroxides and mechanism of peroxy radical recombination". In The Chemistry of Peroxides, Vol. 1, Part 1, J. F. Liebman, A. Greer (Eds.). John Wiley \& Sons, Ltd: Chichester, 2014 pp 197-230.
[10] E. W. Schmidt, Hydrazine and Its Derivatives: Preparation, Properties, Applications, $2^{\text {nd }}$ ed., Wiley-Interscience: New York, 2001.

[11] K.-H. Linke, H. J. Göhausen, Chem. Ber. 1971, 104, 301-306.

[12] N. Egger, L. Hoesch, A. S. Dreiding, Helv. Chim. Acta 1983, 66, 14161426.

[13] T. Kanzian, H. Mayr, Chem. - Eur. J. 2010, 16, 11670-11677.

[14] A. Glowacki, V. Jeux, G. Gasnier, L. Joucla, G. Jacob, E. Lacôte, Synlett 2018, 29, 566-570.

[15] L. A. Wiles, P. Hope, J. Chem. Soc. 1967, 2636-2638.

[16] W. H. Pirkle, P. L. Gravel, J. Org. Chem. 1978, 43, 808-815.

[17] B. Krumm, A. Vij, R. J. Kirchmeier, J. M. Shreeve, H. Oberhammer, Angew. Chem. Int. Ed. Engl. 1995, 34, 586-588.

[18] K. L. Martin, G. W. Breton, Acta Crystallogr. Sect. C 2017, 73, 660-666.

[19] C. Leuenberger, L. Hoesch, A. S. Dreiding, Helv. Chim. Acta 1981, 64, 1219-1233.

[20] L. Hoesch, M. Karpf, E. Dunkelblum, A. S. Dreiding, Helv. Chim. Acta 1977, 60, 816-830.

[21] A. Dhenain, C. Darwich, C. M. Sabate, D.-M. Le, A.-J. Bougrine, H. Delalu, E. Lacôte, L. Payen, J. Guitton, E. Labarthe, et al., Chem.- Eur. J. 2017, 23, 9897-9907.

[22] W. R. McBride, H. W. Kruse, J. Am. Chem. Soc. 1957, 79, 572-576.

[23] W. E. Bull, J. A. Seaton, L. F. Audrieth, J. Am. Chem. Soc. 1958, 80 , 2516-2518.

[24] B. Krumm, R. L. Kirchmeier, J. M. Shreeve, Inorg. Chem. 1995, 34, 5049-5054

[25] T. N. Balasubramaniam, N. R. Natale, Tetrahedron Lett. 1993, 34 1099-1102.

[26] B. Doboszewski, J. McGarrah, A. Y. Nazarenko, F. da Paixao Soares, Acta Crystallogr. Sect. E 2011, 67, 01565.

[27] M. Laing, J. Chem. Educ. 2003, 80, 1057

[28] K. Arumugam, U. Becker, Minerals 2014, 4, 345-387. 
Entry for the Table of Contents (Please choose one layout)

Layout 1:

\section{COMMUNICATION}

Polyazanes up to $5 \sigma$-bonded nitrogen atoms were prepared via sequential additions to diazo reagents. Structural analyses showed that the polynitrogen chains adopt a helical conformation maintained by the carboxyl substituents. The conformations subsist in solution. Polyazanes are increasingly less reducing the more $\mathrm{N}$ atoms are in the chain.
Thomas Criton, Debora Vilona, Guy Jacob, Maurice Médebielle, ${ }^{*}$ Elise Dumont, ${ }^{*}$ Lionel Joucla, ${ }^{*}$ Emmanuel Lacôte*

Page No. - Page No.

Synthesis and Properties of Higher Nuclearity Polyazanes 